\title{
CREATING OPEN EDUCATION RESOURCES FOR TEACHING AND COMMUNITY DEVELOPMENT THROUGH ACTION RESEARCH: THE MILK PRODUCTION AND HYGIENE MODULE
}

\author{
Paul Ssajjakambwe \\ Makerere University \\ Stevens Kisaka \\ Makerere University \\ Patrick Vudriko \\ Makerere University
}

\author{
Christopher Setumba \\ Makerere University
}

Gloria Bahizi

Makerere University

John D. Kabasa

Makerere University

\section{John B. Kaneene \\ Michigan State University}

\begin{abstract}
One of the cornerstones of the AgShare program is the application of an information loop of action research in the training of graduate students to generate new and practical educational materials and interventions for creating open education research (OER) modules for teaching at universities, and for designing interventions and training programs for making improvements in the dairy value chain in Uganda. One major output of the action research project was the generation of data for use in partial fulfillment of a master of science in Agribusiness and a master of science in Livestock Development, Planning, and Management by participating students. A milk production and hygiene OER module was developed based on components in milk safety, dairy policy, contaminants in milk and dairy products, quality assurance, and dairy planning and management. The OER module was incorporated into an existing graduate-level course at Makerere University. As the AgShare approach continuously updates educational materials through the information loop, this program ensures that university training of students is applicable to the current needs of the dairy industry.
\end{abstract}

\section{KEY WORDS}

Open Education Resources; Action Research; Service Learning; Dairy Value Chain; Milk Hygiene; Milk Quality

\section{BACKGROUND}

Ugandan communities need the assistance of trained professionals to improve milk production per cow, product hygiene and safety, transportation, and marketing aspects of milk and milk products. Knowledge and skills in the use of value chain analysis, with dynamic feedback mechanisms that expedite the flow of information between stakeholders (e.g., universities, farmers, milk processors, civic leaders), are required by university graduates and communities seeking to have positive impacts on the Ugandan dairy industry. The College of Veterinary Medicine, Animal Resources and Biosecurity (COVAB), and the College of Agriculture and Environmental Sciences of Makerere University (MAK), in partnership with Michigan State University (MSU) and OER Africa, conducted research and trained students in topics relating to the dairy value chain through the AgShare Program [1]. Research and training was conducted under the first 
phase of AgShare, and resulted in the development of OER-based service learning modules and materials that provide needed information in making improvements in the dairy value chain in Uganda. Two OER modules were developed to address educational needs for improvement of the dairy value chain under AgShare Phase I at Makerere University. The modules consisted of milk production and hygiene, developed under the $\mathrm{COVAB}$, and the management and marketing of milk and milk products, developed under the College of Agriculture and Environmental Sciences. The milk production and hygiene module will be the focus of this paper; the management and marketing of milk and milk products module will be reported in another paper.

\section{DEVELOPMENT OF THE MILK PRODUCTION AND HYGIENE OER MODULE}

One of the important components of the AgShare Program is the use of dynamic information loops for OER-based action research: results of action research are analyzed and used to design interventions to address issues and create educational materials for stakeholders and students. The interventions and educational materials are provided to stakeholders, and action research is used to determine the effects of the interventions and educational materials on the issues they were designed to affect. This approach ensures that educational materials are current and constantly updated, making them more useful for training students than reliance on conventional texts and other educational materials that may be years old, or are based on information from regions and cultures that may have little or no relevance to the communities these students will serve.

To develop the OER learning modules, the project identified and trained two graduate students to function as agents of change in the information loop between academia and stakeholders. The students actively participated in all aspects of action research, including the collection of baseline data to document the status of the dairy value chain, the analysis of data for identification of factors that could be changed to improve performance across the dairy value chain, the design and implementation of interventions for improving the dairy value chain, the determination of intervention influence, and the development of educational materials for the OER based on case materials. The students' experiences in AgShare contributed to meeting the requirements for a master's degree in Livestock Development, Planning, and Management (MSc) or a master's degree in Agribusiness and Management (M Agbus Mgt).

\section{A. Collection and Assessment of Baseline Data}

Baseline information on milk production and hygiene in the Uganda dairy value chain was needed to initiate the information loop process. The baseline information consisted of the following items:

- Qualitative characterization of the dairy value chain was completed in the study area (Kiruhura District), including the characteristics of dairy farms; milk production and production costs; milk consumption; on-farm milk processing; milk marketing; and constraints to dairy production and marketing in the area.

- Quantitative assessment of milk production, hygiene, and quality on farms participating with the AgShare program was also performed in the study area.

Information was collected through three venues: focus group discussions, farm visits for collection of data on the dairy value chain, and farm visits to select farms for collection of biological samples to assess milk quality and safety. After analysis of this information, educational materials and interventions were developed by the AgShare researchers, which were provided to stakeholders through training workshops and demonstrations. After the 12-month intervention period, collection of the same qualitative and quantitative data was repeated on the AgShare farms to allow for evaluation of the effectiveness of the interventions in the community.

\section{Dairy Value Chain Data Collection-Focus Group Discussions}

AgShare researchers, including MAK faculty and the MSc student researchers, convened with different 
stakeholder groups in three focus group meetings to share and exchange perceptions about the challenges and opportunities in the current dairy value chain. They also discussed and planned strategies for improving the dairy value chain (figure 1). The focus groups discussed several questions ranging from milk production, quality milk handling, on-farm milk processing, challenges facing processing, processing opportunities, as well as the marketing of milk and processed dairy products like ghee, cream, and yogurt. The MSc student researchers were involved in planning the meetings, contacting and enlisting members of different stakeholder groups for participation, and guiding discussion during the meetings. Information from the meetings was collected by secretary notes, photographs, and video recording of the discussions. After the focus group meetings, the student researchers and MAK faculty researchers compiled the results of the discussions for use in the baseline data study, and they prepared reports of the results for the stakeholders.



Figure 1. Stakeholder focus group discussion lead by an AgShare MSc student.

\section{Dairy Value Chain Data Collection-Farm Visits}

Farm visits were conducted to assess the status of individual dairy farms in the AgShare study area (figure 2). In the study area (Kiruhura District), four sub-counties were selected for the study (Kinoni, Keshunga, Kikatsi, and Rwemikoma), and a paired matched sampling method was used within each sub-county to select farmers for participation in this study. Approximately 60 farmers were interviewed from each subcounty, and a total of 236 farmers participated in the farm visits. Structured questionnaires were administered by MSc student researchers to every farmer in order to collect information regarding the farm's milk production, milk quality, on-farm milk processing, and different sales channels for selling milk.

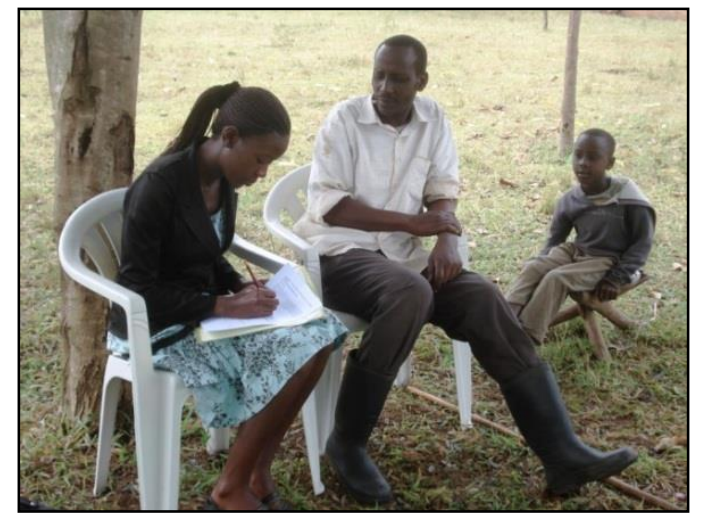

Figure 2. Farm visit interview conducted by an AgShare student.

\section{Milk Production, Hygiene Data, and Sample Collection-Farm Visits}

Farm visits were made to 12 farms for an action research study to determine the prevalence of two important diseases of dairy cattle (mastitis and brucellosis) and levels of hygiene on these farms. Mastitis and brucellosis were selected due to their public health impact, and the widespread prevalence of these diseases in cattle. Six farms were selected by their participation in the Amate Gaitu Cooperative; six other farms 
with a history of high levels of brucellosis were randomly selected by the sub-county veterinarian [2]. The student researchers were involved in contacting and interviewing study farmers, collecting blood and milk samples, conducting laboratory tests for mastitis and brucellosis (figure 3), observing and recording farm hygiene scores, and providing educational materials and training to the 12 participating farms.

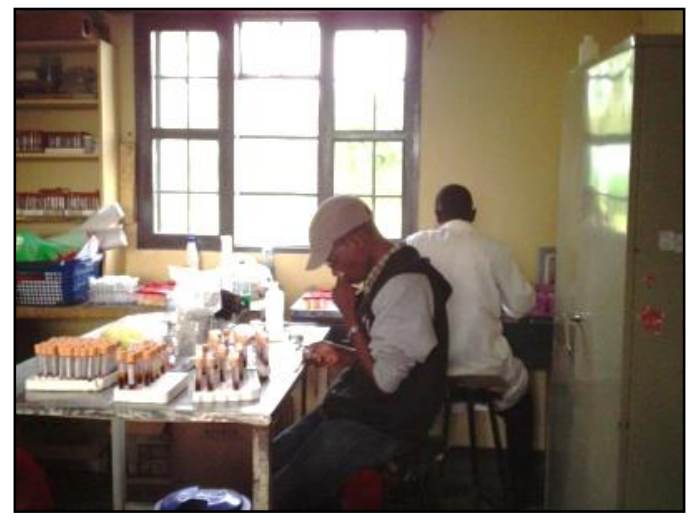

Figure 3. Laboratory testing completed by an AgShare faculty and student.

\section{Analysis and Reports of Dairy Value Chain Data}

Information from focus group meetings and farm visits was compiled and summarized to provide a description of the dairy value chain in the Kiruhura District. Data were gathered on the dairy farm cattle breeds, types of on-farm dairy processing, farmers' primary milk buyers, costs of dairy production per farm, and lists of constraints to milk production (e.g., veterinary drug costs, animal diseases) and milk marketing (e.g., high transportation costs, poor infrastructure, such as poor roads and lack of electrification). These data were used by MAK researchers to formulate interventions to overcome some of the milk production and marketing constraints (e.g., educating farmers in the value of cooperative unions to receive better prices for their milk).

After the analyses were completed, the AgShare team, including the student researchers, held a two-day workshop to disseminate the survey results in the Kiruhura District. This workshop was attended by dairy farmers, milk traders, and local government staff. The major aim of the workshop was to disseminate research findings to dairy farmers, highlighting the performance of and challenges faced by their farms, the current opportunities to be exploited, and to forge the way forward with regards to improving dairy value chain efficiency. In the workshop, both farmers and traders reached consensus that farmers need to be organized if they are to benefit from dairying: the formation of a dairy farmers' marketing organization was discussed.

Information from the dairy value chain analysis was used as the foundation for a separate training workshop for dairy farmers, traders, and milk processors. The objectives of the training workshop were to share knowledge and skills on quality milk production, handling, and processing; equip dairy farmers, especially those doing on-farm processing, with appropriate technologies for processing milk products; and expose farmers, traders, and processors to strategic milk marketing strategies. Trainees were awarded certification by the Department of Agribusiness and Natural Resource Economics in collaboration with the Uganda Dairy Development Authority. The certificates authorized all the trainees to check for milk quality, provide advice to other stakeholders in the dairy value chain, and take legal action when proper milk processing and handling practices were not being followed.

\section{Analysis and Reports of Milk Production and Hygiene Data}

For samples collected at the beginning of the study (baseline data) and at the end of the intervention period, the laboratory results for the existence of mastitis and brucellosis were used to estimate the prevalence of these diseases in the study area's dairy cattle. The prevalence of each disease was reported for each subcounty and for each dairy herd. Hygiene was also analyzed by applying a five-point score (with $0=$ poor, $4=$ excellent) to reflect the level of hygiene on the farm. This score was based on the researchers' evaluation 
of the cleanliness of animals, animal facilities, milking facilities, milking equipment, cow udders before milking, and the personal hygiene of the milkers. The hygienic quality of milk was evaluated by the use of sieves to filter milk before storage and shipping, and the somatic cell count of the milk (an indicator of inflammation/infection in the udder). Hygiene scores were calculated for each farm, and aggregate hygiene scores were generated for each sub-county. These findings were included in the Brucellosis and Mastitis Herd \& Milk Cleanness Score Card, a summary of the baseline study prepared by the COVAB (available at the OER Africa AgShare website).

The quantitative results of this assessment gauged the progress of dairy farmers receiving AgShare training and interventions: comparisons of disease levels and hygiene on farms before and after training/intervention were made to determine the effectiveness of different interventions or training programs on farmers. Findings from these analyses are being prepared by the MSc students and MAK faculty for publication in refereed scientific journals.

Information from the baseline analysis was also used by the AgShare team to provide dairy farmers, processors, and traders with practical lessons on various dairy value chain aspects, such as the quality of milk handling, lactometer tests, and milk processing. Among these lessons were demonstrations that taught farmers how to maintain milk quality on the farm and in transfer to milk collection centers. Dairy farmers were also taught how to prepare quality yogurt for both home consumption and market sale by pasteurizing milk and applying indirect heating. These lessons not only assisted the farmers, but also taught the MSc students critical interpersonal skills and effective teaching strategies that can be applied to future client collaboration. Further, these lessons yielded clear changes in stakeholder activities, which improved the quality of dairy products on the farm and bolstered student confidence and pride in making direct and visible positive impacts (figure 4).

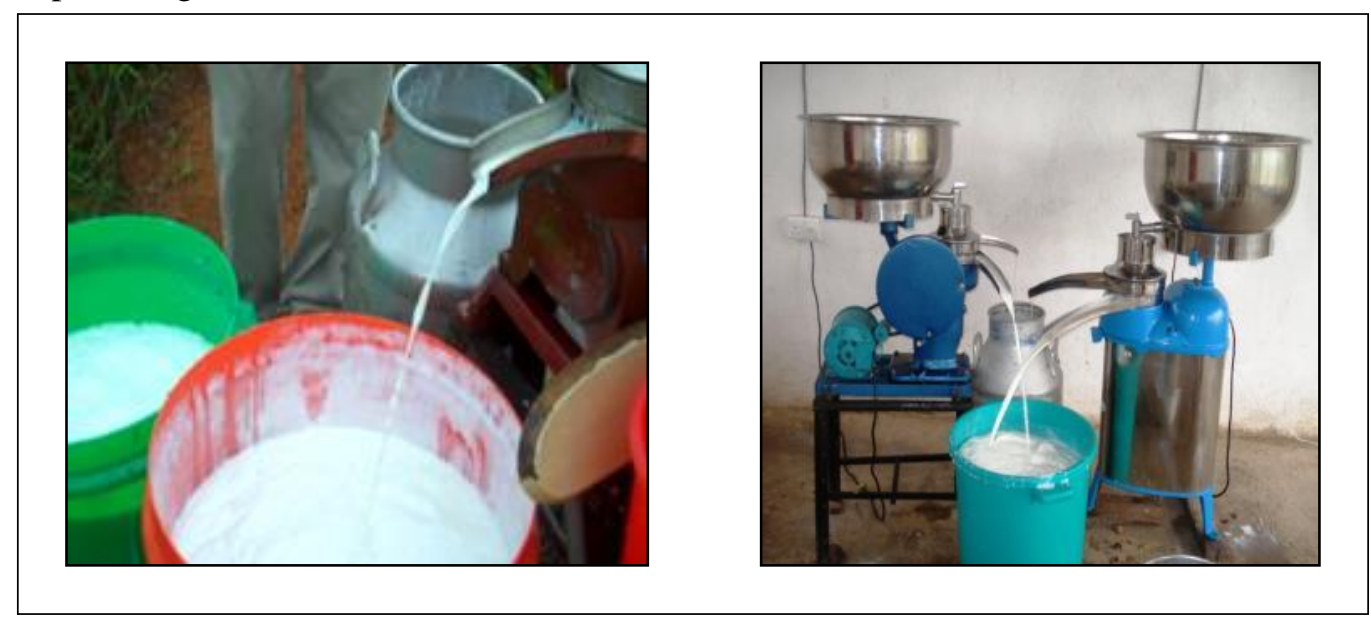

Figure 4. Example of changes in stakeholder practices, from using manual cream separation in 2010 (L) to using an electric separator in 2011 (R).

\section{B. OER Module Development}

Information generated by the baseline study was used to develop an OER teaching module on milk production and hygiene. Faculty members at MAK and MSU, AgShare researchers, and the MSc students participated in the development and writing of different sections of the module (figure 5). The module was divided into six topics:

1. Concepts of milk safety

2. The dairy industry, governance, policy, and legislation in Uganda

3. Infectious contaminants of milk and milk products

4. Non-infectious contaminants of milk and milk products

5. Quality assurance and control of milk and milk products 
6. Contemporary "from-farm-to-table" approaches in dairy planning and management

Topics included working examples from the action research results and lists of references for additional information when pertinent. Case study reports were also developed from action research findings. The case studies, consisting of videos, picture catalogs, and MSc theses and other reports, were designed to highlight specific aspects of the dairy value chain for use by educators in conjunction with the OER module.

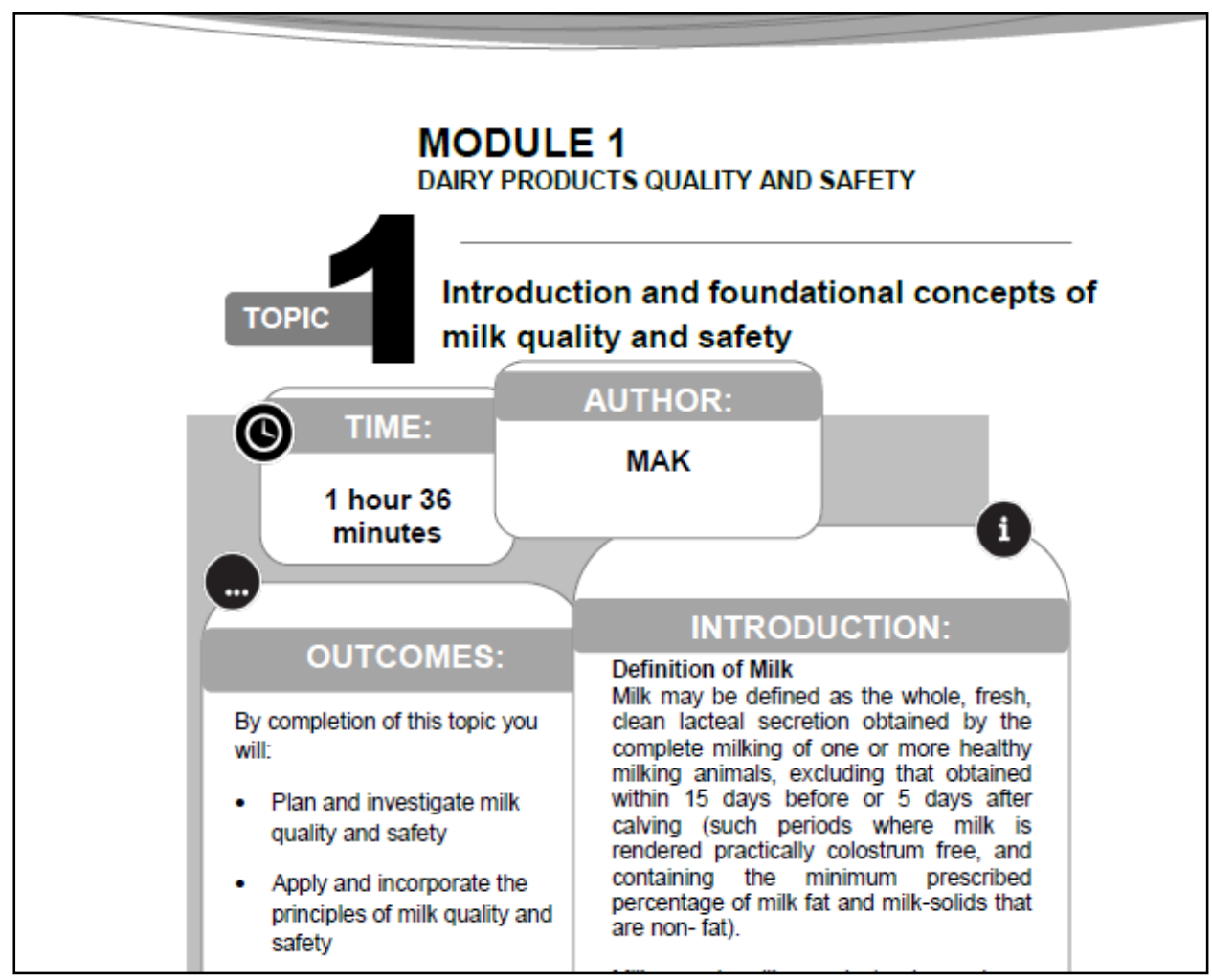

Figure 5. Sample page depicted from the milk production and hygiene module.

\section{USE OF THE MILK PRODUCTION AND HYGIENE OER MODULE}

\section{A. Use of the OER Module at Makerere University}

The milk production and hygiene OER module has been incorporated into the curriculum for the MSc degree in Livestock Development, Planning, and Management in the COVAB at Makerere University. The module is part of the graduate course MLD 7201: Food Safety and Nutrition. The teaching approach of the class focuses on student-centered learning, using the OER module, case studies from AgShare, recommended textbooks, and articles from scientific journals. The course also incorporates community field visits to stimulate the development of communication, interpersonal skills, group dynamics, and service learning. In addition to the direct learning goals of MLD 7201, the community field visits also provides information from the stakeholder communities to contribute to the information loop that drives the AgShare model.

\section{B. Use of the OER Module through OER Africa}

The milk production and hygiene OER module has been made available to interested parties through OER Africa. OER Africa serves as a portal for educators and students to learn about OER, how to benefit and incorporate OER into education programs, and how OER is being used throughout Africa to cover a wide variety of topics. The website serves as an access point for OER content developed by the AgShare Initiative and other projects (e.g., the ACEMaths program for teaching and learning mathematics), and provides search engines and tools for users to locate other sources of OER. The milk production and hygiene module is currently one of six AgShare OER modules, and more modules are planned as the AgShare Program 
continues in Uganda.

\section{SUMMARY}

Development of the milk production and hygiene OER under the AgShare paradigm, using university-led engagement with the community and student researchers as agents of change, a wide range of positive outputs in the community were achieved. It was noted that use of OER materials for teaching at the university and in community training sessions was a very handy technique for relaying the desired messages to the target audience, as long as the presentation of materials is appropriate and appealing to the audience (e.g., videos, pictorials, brochures). The students` direct involvement in communities helped their academic mentors to appreciate the diversity and dynamism of the dairy sector on the ground, which formed a fertile opportunity for the students to become facilitators of change at both the university and in the field.

The development of the OER-based curricula was informed by results from the action research studies, the multi-stakeholder information loop, and video documentation of milk hygiene and agricultural marketing and management events along the whole dairy value chain. These curricula were reviewed by all stakeholder groups, who found that the materials were useful in filling knowledge gaps that riddled the dairy value chain. At the end of the project, independent evaluation of the AgShare approach, using OER for both community and academic training, concluded that the multi-stakeholder information loop system improves the efficiency of the dairy value chain. This innovative approach has achieved several successes in improving community livelihood, as well as in transforming universities into community development institutions.

\section{REFERENCES}

1. Kaneene, J.B., Ssajjakambwe, P., Kisaka, S., Miller, R., and Kabasa, J.D. Creating Open Education Resources for Teaching and Community Development through Action Research: An Overview of the Makerere AgShare Project. Journal of Asynchronous Learning Networks (2013).

2. Kato, M., Nakavuma, J.L., and Nasinyama, G. Microbial Risk Assessment: A Case Study of Brucellosis from Bovine Milk and Milk Products in Kiruhura District-Uganda. A dissertation for the award of Master of Livestock Development, Planning and Management, Makerere University, Kampala, Uganda (2010).

\section{ACKNOWLEDGEMENTS}

The activities of the AgShare Program reported here were supported by funding from the Bill and Melinda Gates Foundation. The authors would also like to thank the following institutions and individuals for their contributions to the project: Makerere University, AFRISA (African Institute for Strategic Animal Resource Services and Development), and the College of Agriculture and Environmental Sciences; Michigan State University - College of Veterinary Medicine, Christine Geith and Karen Vignare of MSU Global Initiative, and RoseAnn Miller of the Center for Comparative Epidemiology; Neil Butcher of OER Africa; SAIDE (South African Institute for Distance Education); and Ken Harley, University of Pretoria.

\section{ABOUT THE AUTHORS}

Paul Ssajjakambwe is an assistant lecturer in the College of Veterinary Medicine, Animal Resources, and Biosecurity, Makerere University, Uganda.

Stevens Kisaka is an assistant lecturer in the College of Veterinary Medicine, Animal Resources, and Biosecurity, Makerere University, Uganda.

Patrick Vudriko is an assistant lecturer in the College of Veterinary Medicine, Animal Resources, and Biosecurity, Makerere University, Uganda.

Christopher Setumba and Gloria Bahizi were the AgShare MSc students at the College of Veterinary Medicine, Animal Resources, and Biosecurity, Makerere University, Uganda.

John D. Kabasa is a professor and principal of the College of Veterinary Medicine, Animal Resources, 
Creating Open Education Resources for Teaching and Community Development through Action Research: The Milk Production and Hygiene Module

and Biosecurity, Makerere University, Uganda.

John B. Kaneene is a University Distinguished Professor of Epidemiology and Director of the Center for Comparative Epidemiology in the College of Veterinary Medicine, Michigan State University, USA. 